Original Research Paper

\title{
Influence of Tags on the Binding Affinity of Acyl-CoA Binding Protein
}

\author{
Jizhong Han, Yunlong Sun, Yu Chen, Haoran Li, Mengmeng Liu and Bin Zeng \\ Jiangxi Key Laboratory of Bioprocess Engineering and Co-Innovation \\ Center for In-vitro Diagnostic Reagents and Devices of Jiangxi Province, \\ College of Life Sciences, Jiangxi Science and Technology Normal University, Nanchang 330013, China
}

Article history

Received: 01-08-2018

Revised: $12-12-2018$

Accepted: 21-01-2019

Corresponding Author: Bin Zeng

Jiangxi Key Laboratory of Bioprocess Engineering and Co-Innovation Center for Invitro Diagnostic Reagents and Devices of Jiangxi Province, College of Life Sciences, Jiangxi Science and Technology Normal University, Nanchang 330013, China Email: zengtx001@aliyun.com

\begin{abstract}
Tagged fusion proteins are frequently employed for protein purification methods, but their effects on protein function and binding affinity are rarely studied. Here we expressed recombinant protein AcylCoA Binding Protein (ACBP) cloned from the full-length cDNA of Aspergillus oryzae and Saccharomyces cerevisiae. ACBP was expressed in Escherichia coli fused to a Maltose-Binding Protein (MBP) and Histidinetag fusion. Recombinant ACBP was purified using affinity chromatography columns and high protein purity was achieved. Microscale Thermophoresis (MST) binding assays showed that recombinant AoAcbp1 had a greater affinity for Palmitoyl-CoA $(\mathrm{Kd}=35 \mathrm{nM})$ and Stearoyl-CoA $(\mathrm{Kd}=23 \mathrm{nM})$ whilst recombinant ScAcbp had a greater affinity for Myristoyl-CoA (Kd = $31 \mathrm{nM})$ and Palmitoyl-CoA $(\mathrm{Kd}=51 \mathrm{nM})$. In addition, MBP tagged ACBP had comparable binding affinities to His-tagged ACBP. Taken together, these data highlight that the size of the tagged fusion protein does not influence protein ACBP binding affinity.
\end{abstract}

Keywords: Acyl-CoA Binding Protein, Tagged Fusion Protein, Affinity Chromatography, Microscale Thermophoresis, Affinity Analysis

\section{Introduction}

Aspergillus oryzae and Saccharomyces cerevisiae are frequently used in industrial biotechnology (Liu et al., 2014) for fatty acid biosynthesis and metabolism, particularly in the fermented food industry (Piras, 2014). A. oryzae is used in the fermentation of rice-based food, soy and sake (Knuf and Nielsen, 2012), due to its high levels of protein secretion and ability to perform posttranslational modifications (Meyer et al., 2011). In addition, S. cerevisiae, commonly known as the fermented yeast of bread and beer, is widely used in food production (Yvert et al., 2003). As the most studied genetic model species, the whole genome sequences of $A$. oryzae and $S$. cerevisiae are widely available (Machida et al., 2005; Wei et al., 2007).

The biosynthesis and degradation of microbial fatty acids is important during fermentation, A. oryzae and yeast always consumed and transformed lipids of soy during its fermentation (Fukushima et al., 1991). Fatty acid oxidation is mediated by fatty acyl-CoA and acylCoA Binding Protein (ACBP) (Wei et al., 2007). ACBP is widely expressed in eukaryotic organisms and pathogenic bacteria (Vock et al., 2006) where is participates in the intracellular transport of acyl-CoAs (Knudsen et al., 2000). Previous studies have characterized the functions of ACBP in A. oryzae and S. cerevisiae. In A. oryzae. ACBP (AoAcbp1) encodes a polypeptide of 365 amino acids that mediates fatty acid metabolism through its interaction with acyl coenzyme A, contributing to the flavor of soy sauce through the metabolism of esters (Bouyakdan et al., 2015). Recently, Kwon et al. (2017) identified another ACBP (AoAcbp2) from A. oryzae, was likely essential for growth. In Hao et al. (2016) indicated that AoAcbp1 has a higher affinity for Palmitoyl-CoA and Stearoyl-CoA, revealed that AoAcbp1 is a long-chain ACBP in A. oryzae. In $S$. cerevisiae, ACBP (ScAcbp) is a highly conserved 10 $\mathrm{kDa}$ protein that is required for vacuole function and ceramide synthesis (Faergeman et al., 2004), ScAcbp activity reduces the levels of hydroxy-C26:0 fatty acids, influences sphingolipid synthesis and regulates the expression of genes involved in fatty acid desaturation (Gaigg et al., 2001). Amino acid sequence homologies between AoAcbp2 with AoAcbp1 and ScAcbp are $12.6 \%$ and $26.4 \%$, respectively. AoAcbp 2 , is widely conserved in fungi and AoAcbp1, is only seen in filamentous fungi, but not in yeasts (Kwon et al., 2017). 
For further study of ACBP, prokaryotic expression and purify is critical. It is convenient for us to study the function, structure and other properties of proteins. Proteins with high purity, simple culture processes, rapid growth and low media costs, are frequently used for protein expression studies. During protein purification, tagged fusion proteins are used for convenience. MaltoseBinding Protein (MBP) is a periplasmic protein of $E$. coli involved in chemotaxis and the uptake of maltose sugars (Reichenwallner et al., 2013). MBP was inserted downstream of the malE gene, resulting in the expression of an MBP fusion (Duplay et al., 1984). Amylose resin can be used as an affinity matrix to purity the MBP tagged protein (Sambrook and Russell, 2006). His-tags contain 6tandem histidine residues that do not influence the solubility or biological function of target proteins (Vijayalakshmi, 2008). N-terminal His-tagged proteins can be purified using one-step Immobilized Metal-chelate Affinity Chromatography (IMAC) (Li et al., 2017; Wang et al., 2017). In past studies, when MBP was used as fusion protein, whether it would affect the function of ACBP, it was uncertainty. Thus, we selected two common tagged fusion proteins for the purification.

In this study, MBP-ACBP and His-tagged ACBP were produced to high purity for the assessment of their binding affinities using Microscale Thermophoresis (MST) technology. Our findings were in agreement with results obtained using ITC and NMR (Pagano et al., 2008). The Monolith NTTM Protein Labeling Kit permits NT-647NHS labeling of small amounts of protein $(2-20 \mathrm{mM})$. Respective $K_{d}$ values were calculated using the mess action equation via Nano Temper software from duplicate reads of triplicate experiments (Wienken et al., 2010). MST was shown to efficiently determine such weak interactions between small fragments and proteins in our system. We reproducibly performed experimental binding measurements using minimal amounts of protein and fragments (Gudim et al., 2017).

\section{Materials and Methods}

\section{Strains, Plasmids and Biochemical Reagent}

Escherichia coli DH5 $\alpha$, E. coli Rosetta (DE3), A. oryzae 3.042 and $S$. cerevisiae S288c were grown in the Jiangxi Province Key Laboratory of Bioprocess Engineering. Vector Pet-28a(+) and PMAL-c4x (Invitrogen, USA) were used to construct recombinant plasmids. Experiment reagents for RNA extraction and molecular biology procedures were purchased from Takara (Dalian, China). Nickel affinity columns and Isopropyl- $\beta-D-1-$ Thiogalactopyranoside (IPTG) were purchased from QIAGEN (Beijing, China). Yeast extract, tryptone, $\mathrm{NaCl}$ and amylose resin were purchased from Sangon Biotech (Shanghai, China). Ni-Agarose Resin was purchased from CWBIO (Beijing, China). Phenylmethanesulfonyl Fluorode
(PMSF) was purchased from Beyotime Biotechnology (Shanghai, China). Each fatty acyl-CoA was purchased from Avanti Polar Lipids, Inc. (Alabama, USA). The Monolith $\mathrm{NT}^{\mathrm{TM}}$ Protein Labeling Kit was purchased from NanoTemper (Germany).

\section{Cloned ACBP and Construction of the Expression Vector}

AoAcbp1 was cloned from A. oryzae 3.042 and ScACBP was cloned from $S$. cerevisiae S288c. pMAL$\mathrm{c} 4 \mathrm{x}$ and Pet-28a vector were used to express recombinant AoAcbp1 and ScAcbp fusion proteins,. Vector Pet-28a $(+)$ has a His-tag in its N-terminus and pMAL-c4x has an MBP in its N-terminus. Pet-28a(+) was used for the expression of the His-tagged AoAcbp1 and ScAcbp fusions. pMAL-c4x was used to produce MBP fusions of AoAcbp1 and ScAcbp.

We found that ACBP from A. oryzae and $S$. cerevisiae encoded proteins of 365 and 87 amino acids in length, respectively. Both proteins contained an ACBP domain, as predicted by the Pfam program (http://pfam.xfam.org). This domain accounted for only a small portion of AoAcbpl. According to predictions from the Pfam program, we expressed a protein that contained domain fragments. This was initially cloned by PCR from $A$. oryzae cDNA using the following primers: AoAcbpl-domain for 5 ' GAATTCATGTCGGACTCTGTGAGGTATGCGTCGC AGACGCC 3 ', Ao Acbpl-domain Rev 5 ' AAGCTTCTAGGGGCATTTATGATACCTTGG 3 '. Underlined sequences were attached for Multisite Gateway cloning. The fragment was ligated to pMAL$\mathrm{c} 4 \mathrm{x}$ to select single clones, confirmed by diagnostic restriction analysis and PCR.

\section{Recombinant Protein Expression}

E. coli is used for recombinant protein expression as it does not inherently secrete proteins into the extracellular environment (Sommer et al., 2009). We constructed a series of expression vectors to facilitate extracellular protein production and purification.

pMAL-AoAcbp1, pMAL-ScAcbp, Pet-AoAcbp1, Pet-ScAcbp and pMAL-AoAcbpl-domain were transformed into E. coli Rosetta (DE3) cells for recombinant expression and the plate count method used to identify transformed cells. Monoclonal colonies were grown in $50 \mathrm{~mL}$ LB containing antibiotics in $250 \mathrm{~mL}$ conical flasks. (pMALAoAcbp1, pMAL-ScAcbp and the pMAL-AoAcbp1domain, media were supplemented $100 \mu \mathrm{g} / \mathrm{mL}$ ampicillin and $34 \mu \mathrm{g} / \mathrm{mL}$ chloramphenicol. For PetAoAcbp1, Pet-ScAcbp added $100 \mu \mathrm{g} / \mathrm{mL}$ kanamycin and $34 \mu \mathrm{g} / \mathrm{mL}$ chloramphenicol were added for selection). Following overnight culture, $2 \mathrm{~mL}$ of cells were added into $200 \mathrm{~mL}$ LB in a $500 \mathrm{~mL}$ conical flask, which was shaken at $25^{\circ} \mathrm{C}$. When the $\mathrm{OD}_{610}$ 
reached $0.4-0.6,0.5 \mathrm{mM}$ IPTG was added and cells were collected after $16 \mathrm{~h}$ culture at $18^{\circ} \mathrm{C}$.

\section{Purification of Fusion-Tagged Proteins}

For purification, cultured cells centrifuged at 12000 rpm for $20 \mathrm{~min}$ and resuspended in binding buffer on ice. Cells were sonicated for $10 \mathrm{~min}$, centrifuged at 12000 rpm for $20 \mathrm{~min}$ and supernatants were collected. Recombinant proteins were purified using affinity chromatography columns.

pMAL-AoAcbp1, pMAL-ScAcbp, pMAL-AoAcbp1domain possessed tagged MBP proteins with affinity for adsorption on amylose resin chromatography columns. MBP fusions remained bound in binding buffer $(20 \mathrm{Mm}$ Tris- $\mathrm{HCl}, 200 \mathrm{Mm} \mathrm{NaCl}, 1 \mathrm{Mm}$ EDTA, $\mathrm{pH} \mathrm{7.4)} \mathrm{and}$ were eluted in buffer containing $5 \mathrm{mM}$ maltose.

Pet-AoAcbp1, Pet-ScAcbp have His-fusions with affinity for adsorption on Ni-NTA columns. His-tagged proteins remained bound to the column in the presence of washing buffer and were eluted by buffer containing $250 \mathrm{mM}$ imidazole. Purified proteins were confirmed by SDS-PAGE and Coomassie blue staining.

\section{Microscale Thermophoresis Binding Assays}

The use of the Monolith $\mathrm{NT}^{\mathrm{TM}}$ Protein Labeling Kit, provides a convenient method of labeling purified AoAcbp1 and ScAcbp. Column A (for buffer exchange) permits protein purification in a buffer that lacks contain primary amines or imidazole. Proteins were mixed with NT-647-NHS dye 1:1 ratio (200 $\mu \mathrm{L}$ final volume) and incubated for $30 \mathrm{~min}$ at room temperature in the dark. Column B (gravity flow column for purification) was used to remove unbound dye and eluted fractions were assessed for fluorescent intensity suing the Monolith device. For this assays, 16 serial dilutions of the sample were produced and diluted 1:1 with fluorescently labeled protein. Sample were mixed for $5 \mathrm{~min}$ at room temperature and loaded into the NanoTemper glass capillaries to initiate MST analysis in a NanoTemper monolith NT.115 (California USA).

As a control, we expressed Pmal-c4x without ACBP and identically to pMAL-ScAcbp, to obtain MBP, verified whether MBP has affinity with each fatty-acids.

\section{Results and Discussion}

Cloning of the ACBP from A. oryzae and $S$. cerevisiae

AoAcbp1 from $A$. oryzae 3.042 was $77 \%$ identical to A. fumigatus, A. clavatus, A. nomius and $99 \%$ identical to A. flavus (Yao et al., 2016). AoAcbpl (GenBank accession number Ao3042_01296) was cloned and expressed as a MBP-AoAcbp1 fusion (purified by a step gradient of maltose) and a His-AoAcbpl fusion (purified with a step gradient of imidazole). GFP-tagged AoAcbpl localizs to punctate structures in the cytoplasm and is transported to vacuoles via the autophagy machinery (Kawaguchi et al., 2016). AoAcbp2 displays diffuse cytoplasmic staining (Kwon et al., 2017). ScAcbp cDNA (GenBank accession number YGR037C) from $S$. cerevisiae S288c, a highly conserved sequence (Gaigg et al., 2001), was cloned and expressed as an MBP-ScAcbp fusion and His-ScAcbp fusion and purified as described for AoAcbp1. Multiple alignment of the AoAcbp1 domain from several species revealed its importance to acyl-CoA binding activity, particularly Tyr and Lys residues which are evolutionarily conserved (Hao et al., 2016). Fragments containing the AoAcbpl-domain were confirmed by sequencing analysis (Sangon Corporation).

\section{Prokaryotic Expression and Protein Purification}

The expression vector was transformed into E. coli Rosetta (DE3) for protein expression. Bacteria were induced under varying temperatures and IPTG concentrations to ensure optimal purification conditions, confirmed by SDS-PAGE. Induction with $0.5 \mathrm{mM}$ IPTG at $18^{\circ} \mathrm{C}$ produced the highest levels of recombinant proteins expression. To purify MBP tagged proteins, crude samples were loaded into amylose resin chromatography columns which were eluted with washing buffer. A Niagarose resin column was used for and His-tagged fusion proteins. Purified fusions were analyzed by SDS-PAGE.

MBP-AoAcbp1 had a molecular weight of $\sim 82 \mathrm{kDa}$ (Fig. 1, lane.1), MBP-ScACBP = 52 kDa (Fig. 1, lane.2), His-AoAcbpl = $40 \mathrm{kDa}$ (Fig. 1, lane.3), His-ScACBP = $10 \mathrm{kDa}$ (Fig. 1, lane.4), MBP-AoAcbpl-Domain = 53 kDa (Fig. 1, lane.5), MBP = 42 kDa (Fig. 1, lane.6), All fusion proteins were of the predicted molecular weight.

\section{Microscale Thermophoresis Binding Assays}

Gravity flow and spin columns were used to purify the labeled proteins. MST analysis revealed that MBPAoAcbp1 and His-AoAcbp1 had a binding preference for Stearoyl-CoA and Eicosanoyl-CoA (Table 1) $\left(\mathrm{K}_{\mathrm{d}}\right.$ values and response curves are shown in Fig. S1 and S2) and the linear relativity shown that $K_{d}$ values (MBPAoAcbp1 and His-AoAcbp1 with each fatty acyl-CoA) had no significant difference and had good linear correlation (Fig. 2A). MBP-ScAcbp and His-ScAcbp had a binding preference for Myristoyl-CoA and PalmitoylCoA (Table 2) $\left(\mathrm{K}_{\mathrm{d}}\right.$ values and response curves are shown in Fig. S3 and Fig. S4) and the linear relativity shown that $\mathrm{K}_{\mathrm{d}}$ values (MBP-ScAcbp and His-ScAcbp with each fatty acyl-CoA) had no significant difference and had good linear correlation (Fig. 2B). In addition, from the $\mathrm{K}_{\mathrm{d}}$ values (C4-C20), the presence of MBP or the His-tag did not influence the acyl-CoA binding affinity. The MBPAoAcbp1-domain bound strongly to fatty acyl-CoA (C12:0-C18:0) (Fig. 3). As a control, MBP had no binding affinity with fatty acyl-CoA (C12:0-C18:0) (Fig. 4). 

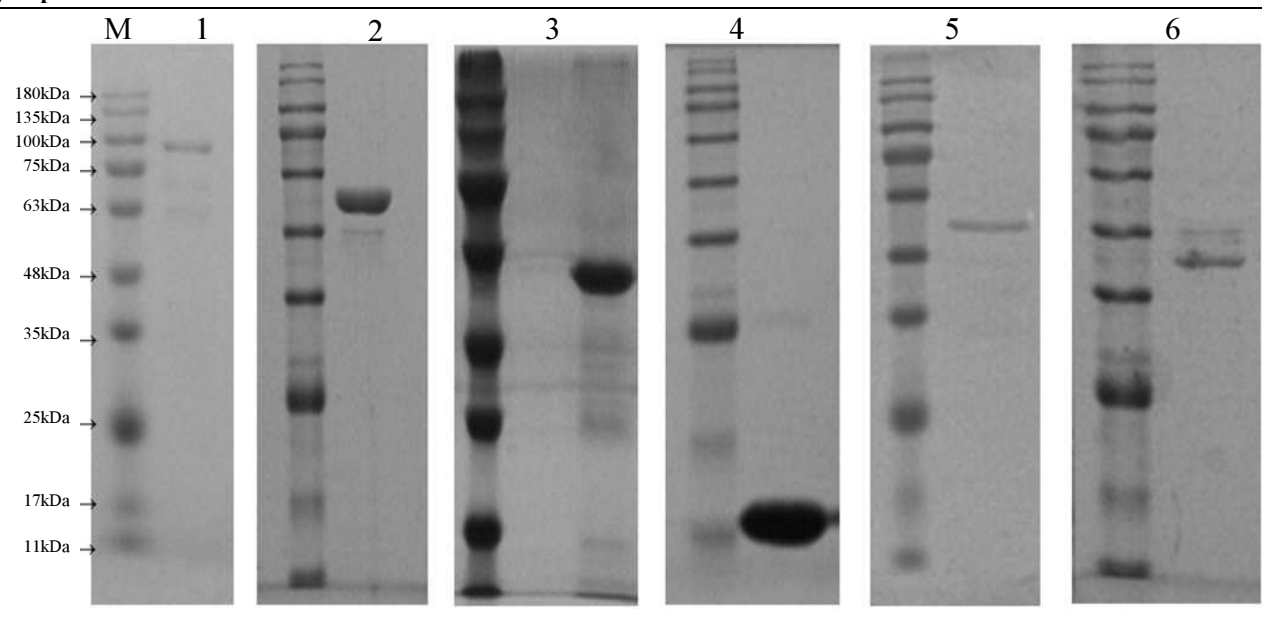

Fig. 1: Coomassie staining of purified recombinant proteins; M protein marker, 1 MBP-AoAcbp1, 2 His-AoAcbp1, 3 MBP-ScAcbp, 4 His-ScAcbp, 5 MBP-AoAcbp1-domain, 6 MBP
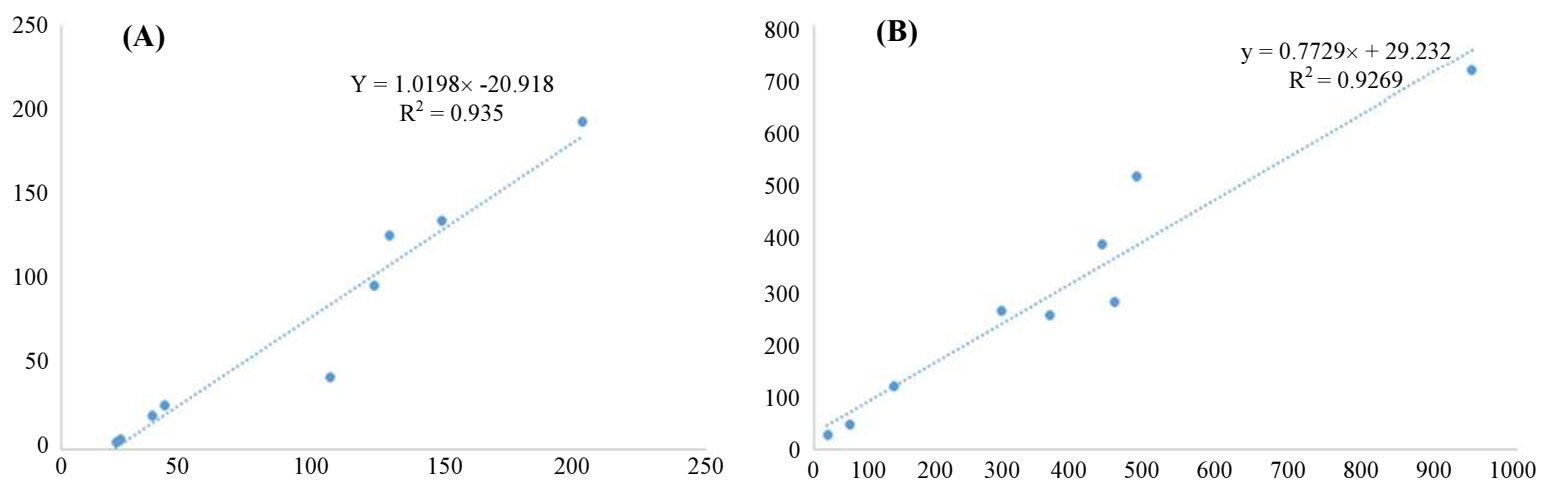

Fig. 2: Linear correlation curve (A) the linear relativity of $K_{d}$ values (MBP-AoAcbp1 and His-AoAcbp1 with each fatty acyl-CoA) (B) the linear relativity of $\mathrm{K}_{\mathrm{d}}$ values (MBP-ScAcbp and His-ScAcbp)

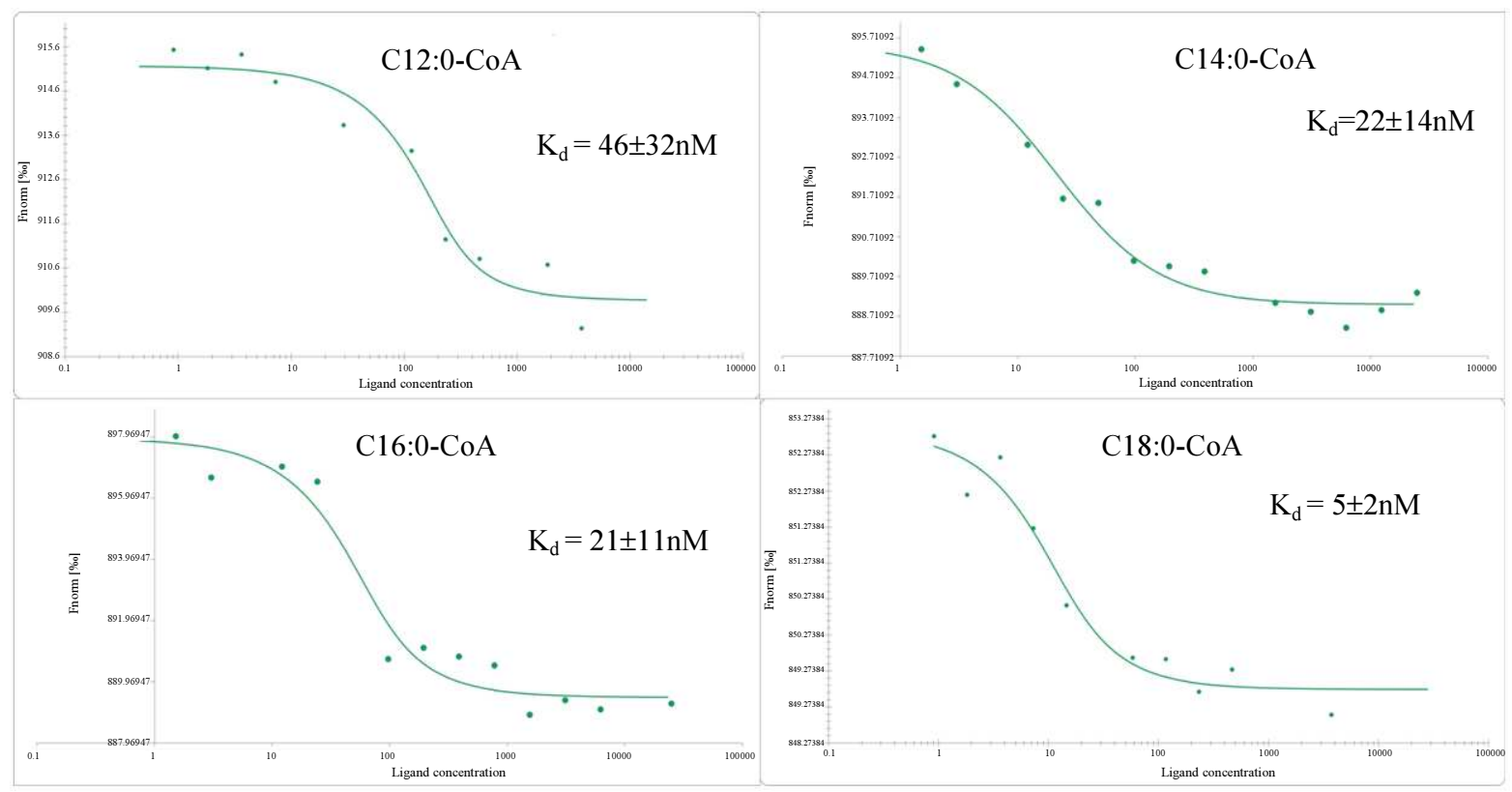

Fig. 3: Concentration response curve for MBP-AoAcbp1-domain ligand binding assessed by MST 


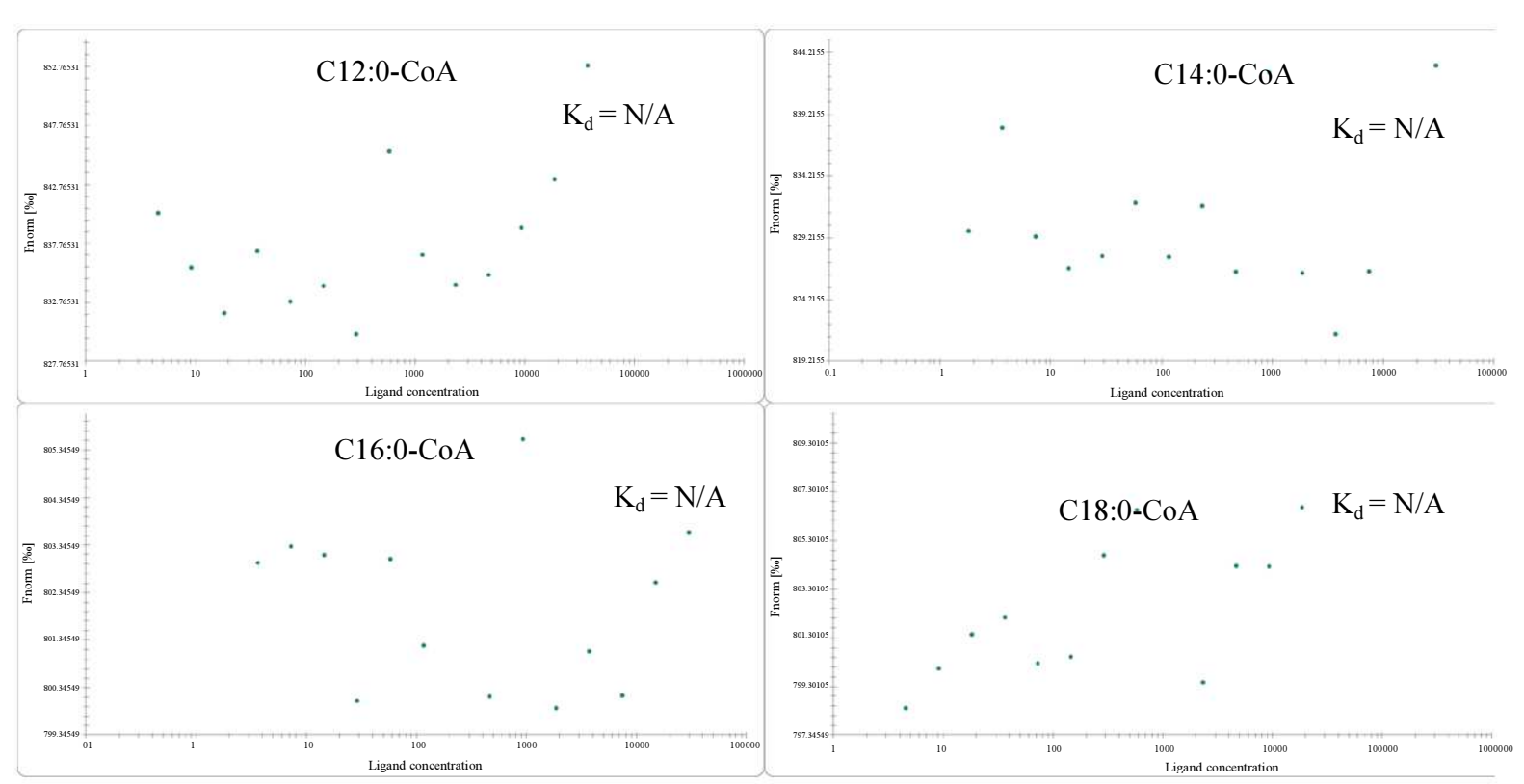

Fig. 4: Concentration response curve for MBP ligand binding assessed by MST

Table 1: MST assessment of $K_{d}$ values revealing the binding affinity of MBP-AoAcbp1 and His-AoAcbp1 with each fatty acyl-CoA

\begin{tabular}{lllll}
\hline Numbers & Carbon numbers & Species & $\begin{array}{l}\mathrm{K}_{\mathrm{d}} \text { value of } \\
\text { MBP-AoACBP (nM) }\end{array}$ & $\begin{array}{l}\mathrm{K}_{\mathrm{d}} \text { value of } \\
\text { His-AoACBP (nM) }\end{array}$ \\
\hline 1 & C4:0 & Butyryl-CoA & $202 \pm 114$ & $193 \pm 130$ \\
2 & C6:0 & Hexanoyl-CoA & $147 \pm 84$ & $135 \pm 123$ \\
3 & C8:0 & Octanoyl-CoA & $127 \pm 99$ & $126 \pm 244$ \\
4 & C10:0 & Decanoyl-CoA & $121 \pm 62$ & $96 \pm 71$ \\
5 & C12:0 & Dodecanoyl-CoA & $104 \pm 29$ & $42 \pm 19$ \\
6 & C14:0 & Myristoyl-CoA & $40 \pm 17$ & $26 \pm 22$ \\
7 & C16:0 & Palmitoyl-CoA & $35 \pm 14$ & $20 \pm 14$ \\
8 & C18:0 & Stearoyl-CoA & $23 \pm 12$ & $6 \pm 2$ \\
9 & C20:0 & Eicosanoyl-CoA & $21 \pm 11$ & $4 \pm 3$ \\
\hline
\end{tabular}

Table 2: MST assessment of $\mathrm{K}_{d}$ values revealing the binding affinity of MBP-ScAcbp and His-ScAcbp with each fatty acyl-CoA

\begin{tabular}{lllll}
\hline Numbers & Carbon numbers & Species & $\begin{array}{l}\mathrm{K}_{\mathrm{d}} \text { value of } \\
\text { MBP-ScACBP }(\mathrm{nM})\end{array}$ & $\begin{array}{l}\mathrm{K}_{\mathrm{d}} \text { value of } \\
\text { His-ScACBP }(\mathrm{nM})\end{array}$ \\
\hline 1 & C4:0 & Butyryl-CoA & $936 \pm 500$ & $716 \pm 186$ \\
2 & C6:0 & Hexanoyl-CoA & $460 \pm 175$ & $514 \pm 268$ \\
3 & C8:0 & Octanoyl-CoA & $410 \pm 190$ & $387 \pm 216$ \\
4 & C10:0 & Decanoyl-CoA & $267 \pm 144$ & $262 \pm 199$ \\
5 & C12:0 & Dodecanoyl-CoA & $114 \pm 68$ & $119 \pm 72$ \\
6 & C14:0 & Myristoyl-CoA & $20 \pm 17$ & $26 \pm 24$ \\
7 & C16:0 & Palmitoyl-CoA & $51 \pm 20$ & $45 \pm 30$ \\
8 & C18:0 & Stearoyl-CoA & $335 \pm 187$ & $251 \pm 88$ \\
9 & C20:0 & Eicosanoyl-CoA & $428 \pm 206$ & $278 \pm 129$ \\
\hline
\end{tabular}

The MST data revealed that AoAcbp1 has a high specificity and affinity for long-chain acyl-CoA esters. Thus AoAcbp1 is a long chain ACBP. Furthermore, no binding was detected for each fatty acyl-CoA to the MBP tag (Hao et al., 2016), demonstrating that binding is AoAcbp1 specific. AoAcbpl and ScAcbp had a preference for binding relatively long chain acyl-CoAs, that conform to the fatty acid composition of $A$. oryzae 3.042 and S. cerevisiae S288c.
In summary, we provide insight into the binding affinity and specificity of AoAcbpl and ScAcbp for fatty acyl-CoA. Comparable affinity was observed between MBP and Histags of ACBP from A. oryzae and S. cerevisiae. In addition, no non-specific binding of the inserted tags was observed. To date, protein crystallization typically employs Histagged fusions for protein purification. As no influence of the tags was observed, MBP-tagged fusions are also applicable for crystallography studies and do not influence. 


\section{Funding Information}

This work was supported by Jiangxi Province Key Laboratory of Bioprocess Engineering and Co-Innovation Center for in vitro Diagnostic Reagents and Devices of Jiangxi Province and these projects in China ("555 talent project" of Jiangxi Province, Nos. 31460447, 20142BDH80003, 31171731 and 2013-CXTD002).

\section{Author's Contributions}

Jizhong Han: Has contributed in whole experiment, data analysis, paper writing and publishment.

Yunlong Sun: Has assisted in the experiment and coordinated the data-analysis.

Haoran Li, Mengmeng Liu and Yu Chen: Have contributed to the acquisition of data and modification of the manuscript.

Bin Zeng: Has conceived and designed the experiments and contributed to get support for this work.

\section{Ethics}

This article is original and contains unpublished material. The corresponding author confirms that all of the other authors have read and approved the manuscript and there are no ethical issues involved.

\section{References}

Bouyakdan, K., B. Taib, L. Budry, S. Zhao and D. Rodaros et al., 2015. A novel role for central $\mathrm{ACBP} / \mathrm{DBI}$ as a regulator of long-chain fatty acid metabolism in astrocytes. J. Neurochem., 133: 253-265. DOI: 10.1111/jnc.13035

Duplay, P., H. Bedouelle, A. Fowler, I. Zabin and W. Saurin et al., 1984. Sequences of the malE gene and of its product, the maltose-binding protein of Escherichia coli K12. J. Biol. Chem., 259: 10606-10613. PMID: 6088507

Faergeman, N.J., S. Feddersen, J.K. Christiansen, M.K. Larsen and R. Schneiter et al., 2004. Acyl-CoAbinding protein, Acblp, is required for normal vacuole function and ceramide synthesis in Saccharomyces cerevisiae. Biochem. J., 380: 907-918.

DOI: $10.1042 / \mathrm{bj} 20031949$

Fukushima, Y., H. Itoh, T. Fukase and H. Motai, 1991. Stimulation of protease production by Aspergillus oryzae with oils in continuous culture. Applied Microbiol. Biotechnol., 34: 586-590. DOI: $10.1007 / \mathrm{BF} 00167904$

Gaigg, B., T.B. Neergaard, R. Schneiter, J.K. Hansen, N.J. Faergeman et al., 2001. Depletion of acylcoenzyme A-binding protein affects sphingolipid synthesis and causes vesicle accumulation and membrane defects in Saccharomyces cerevisiae. Molecular Biol. Cell, 12: 1147-1160.

DOI: $10.1091 / \mathrm{mbc} .12 .4 .1147$
Gudim, I., M. Lofstad, M. Hammerstad and H.P. Hersleth, 2017. Measurement of FNR-NrdI interaction by Microscale Thermophoresis (MST). Bio-Protocol, 7: e2223-e2223. DOI: $10.21769 /$ BioProtoc.2223

Hao, Q., X. Liu, G. Zhao, L. Jiang and M. Li et al., 2016. Recombinant expression, purification and characterization of an acyl-CoA binding protein from Aspergillus oryzae. Biotechnol. Lett., 38: 519-525. DOI: 10.1007/s10529-015-2003-1

Kawaguchi, K., T. Kikuma, Y. Higuchi, K. Takegawa and K. Kitamoto, 2016. Subcellular localization of acyl-CoA binding protein in Aspergillus oryzae is regulated by autophagy machinery. Biochem. Biophys. Res. Commun., 480: 8-12. DOI: $10.1016 /$ j.bbrc.2016.10.018

Knudsen, J., T.B. Neergaard, B. Gaigg, M.V. Jensen and J.K. Hansen, 2000. Role of acyl-CoA binding protein in acyl-CoA metabolism and acyl-CoAmediated cell signaling. J. Nutr., 130: 294S-298S. DOI: $10.1093 / \mathrm{jn} / 130.2 .294 \mathrm{~S}$

Knuf, C. and J. Nielsen, 2012. Aspergilli: Systems biology and industrial applications. Biotechnol. J., 7: 1147-1155. DOI: 10.1002/biot.201200169

Kwon, H.S., K. Kawaguchi, T. Kikuma, K. Takegawa and K. Kitamoto et al., 2017. Analysis of an acylCoA binding protein in Aspergillus oryzae that undergoes unconventional secretion. Biochem. Biophys. Res. Commun., 493: 481-486. DOI: 10.1016/j.bbrc.2017.08.166

Li, S., K. Yang, L. Liu, B. Zhao and Y. Chen et al., 2017. Surface sieving coordinated IMAC material for purification of His-tagged proteins. Analytica Chim. Acta, 9-15.

Liu, L., A. Feizi, T. Österlund, C. Hjort and J. Nielsen, 2014. Genome-scale analysis of the high-efficient protein secretion system of Aspergillus oryzae. BMC Syst. Biol., 8: 1-13. DOI: 10.1186/1752-0509-8-S3-S1

Machida, M., K. Asai, M. Sano, T. Tanaka and T. Kumagai et al., 2005. Genome sequencing and analysis of Aspergillus oryzae. Nature, 438: 1157-1161. DOI: 10.1038/nature04300

Meyer, V., B. Wu and A.F. Ram, 2011. Aspergillus as a multi-purpose cell factory: Current status and perspectives. Biotechnol. Lett., 33: 469-476. DOI: $10.1007 / \mathrm{s} 10529-010-0473-8$

Pagano, B., A. Virno, C.A. Mattia, L. Mayol and A. Randazzo et al., 2008. Targeting DNA quadruplexes with distamycin A and its derivatives: An ITC and NMR study. Biochimie, 90: 1224-1232. DOI: $10.1016 /$ j.biochi.2008.03.006

Piras, A., 2014. Impact of dietary Conjugated Linoleic Acid (CLA) on fatty acid metabolism and endocannabinoid biosynthesis. 
Reichenwallner, J., M. Chakour, S. Indu, R. Varadarajan and W.E. Trommer, 2013. Maltose binding protein is partially structured in its molten globule state. Applied Magnetic Resonance, 44: 983-995. DOI: $10.1007 / \mathrm{s} 00723-013-0468-4$

Sambrook, J. and D.W. Russell, 2006. Purification of maltose-binding fusion proteins by affinity chromatography on amylose resin. Csh Protoc.

Sommer, B., K. Friehs, E. Flaschel, M. Reck and F. Stahl et al., 2009. Extracellular production and affinity purification of recombinant proteins with Escherichia coli using the versatility of the maltose binding protein. J. Biotechnol., 140: 194-202. DOI: $10.1016 /$ j.jbiotec.2009.01.010

Vijayalakshmi, M.A., 2008. Immobilized metal ion affinity systems for recovery and structure function studies of proteins at molecular, supramolecular and the cellular levels. J. Biotechnol., 136: S286-S286. DOI: 10.1016/j.jbiotec.2008.07.614

Vock, C., K. Biedasek, I. Boomgaarden, A. Heins and I. Nitz et al., 2006. ACBP knockdown leads to downregulation of genes encoding rate-limiting enzymes in cholesterol and fatty acid metabolism. Cellular Physiol. Biochem., 25: 675-686.

DOI: $10.1159 / 000315087$
Wang, M.M., Q. Chen, D.D. Zhang, X.W. Chen and M.L. Chen, 2017. Tetra-nickel substituted polyoxotungsate as an efficient sorbent for the isolation of His6-tagged proteins from cell lysate. Talanta, 171: 173-178.

DOI: $10.1016 /$ j.talanta.2017.04.079

Wei, W., J.H. Mccusker, R.W. Hyman, T. Jones and Y. Ning et al., 2007. Genome sequencing and comparative analysis of Saccharomyces cerevisiae strain YJM789. Proc. Nat. Acad. Sci. USA, 104: 12825-12830. DOI: 10.1073/pnas.0701291104

Wienken, C.J., P. Baaske, U. Rothbauer, D. Braun and S. Duhr, 2010. Protein-binding assays in biological liquids using microscale thermophoresis. Nat Commun., 1: 100-100. DOI: 10.1038/ncomms 1093

Yao, Y., C. Ouyang, L. Jiang, X. Liu and Q. Hao et al., 2016. Specificity of acyl-CoA binding protein to acyl-CoAs: Influence on the lipid metabolism in Aspergillus oryzae. RSC Adv., 6: 94859-94865. DOI: 10.1039/c6ra20532a

Yvert, G., R.B. Brem, J. Whittle, J.M. Akey and E. Foss et al., 2003. Trans-acting regulatory variation in Saccharomyces cerevisiae and the role of transcription factors. Nature Genet., 35: 57-64. DOI: $10.1038 /$ ng 1222

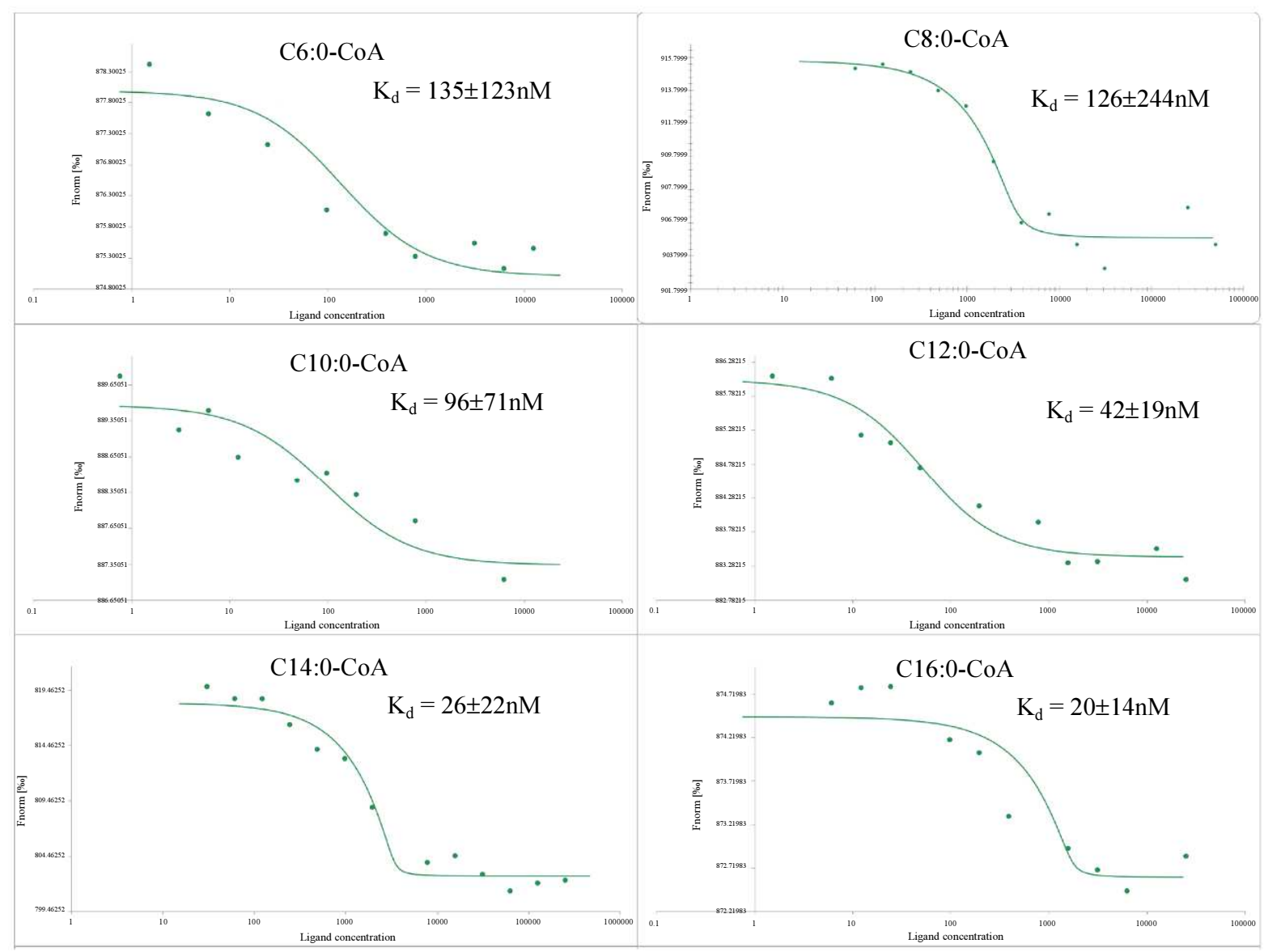




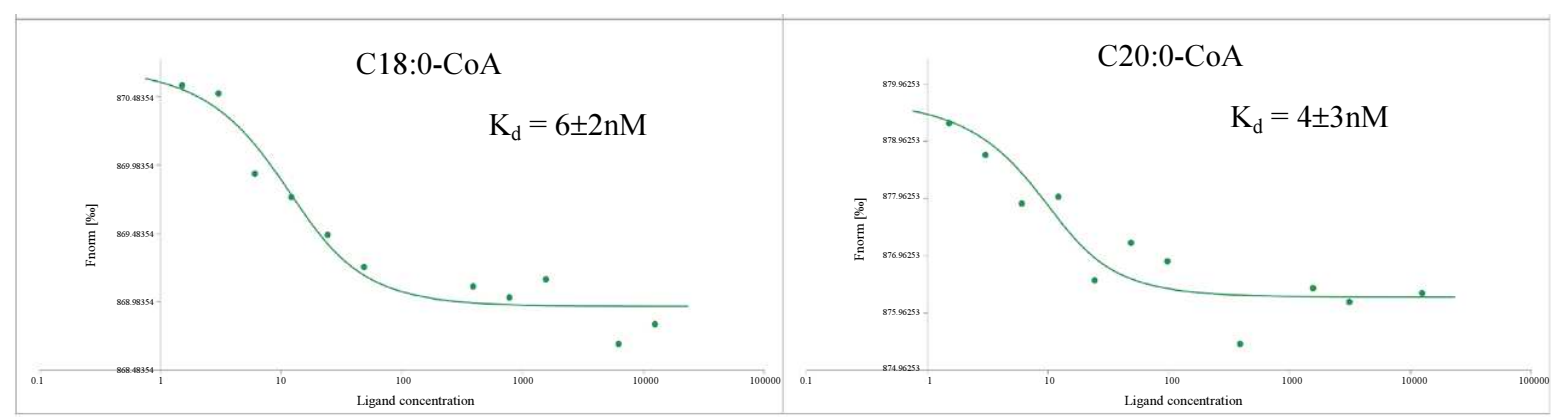

Fig. S1: Concentration response curve for His-AoAcbp1 ligand binding assessed by MST

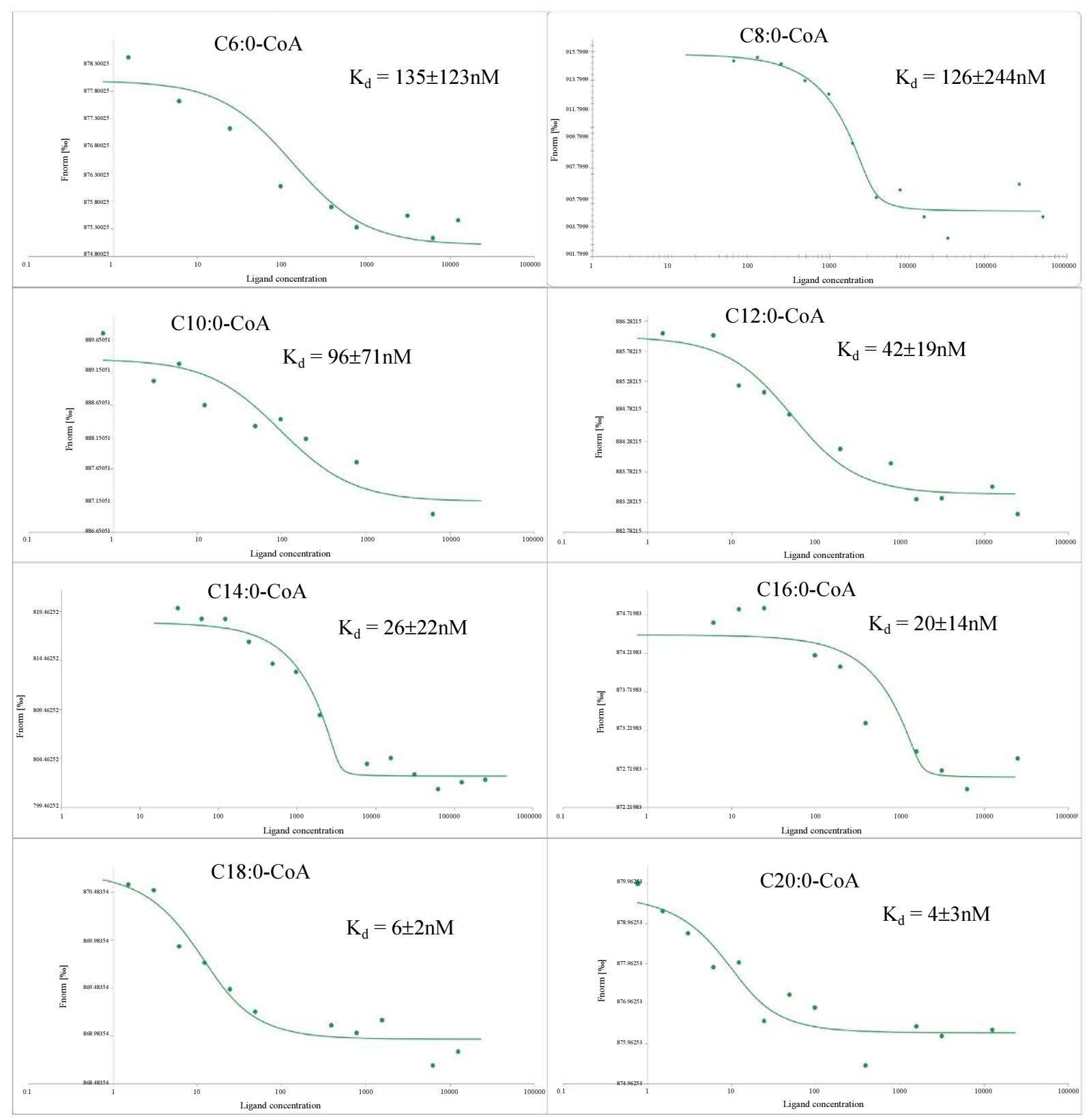

Fig. S2: Concentration response curve for MBP-AoAcbp1 ligand binding assessed by MST 


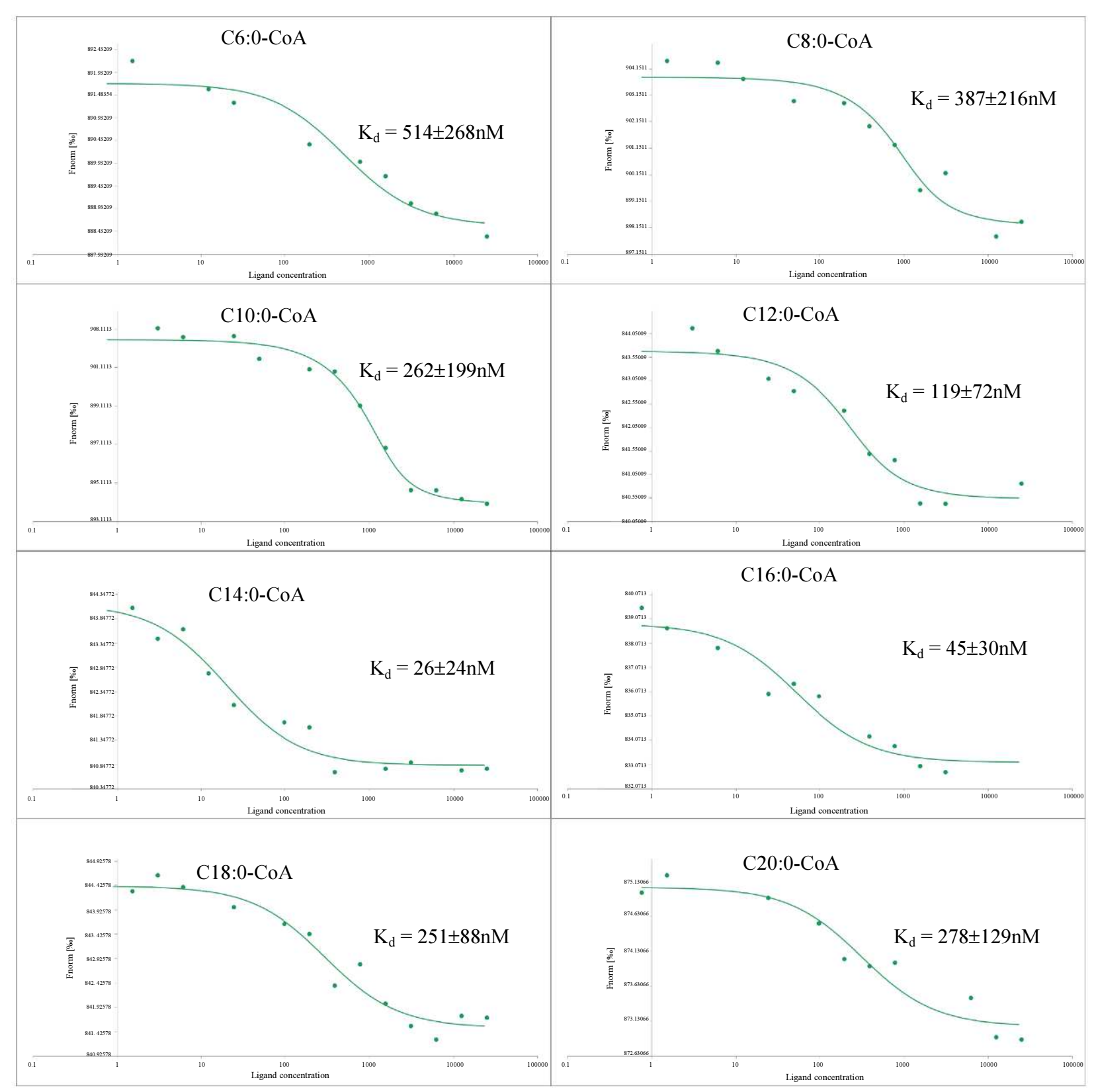

Fig. S3: Concentration response curve for His-ScAcbp ligand binding assessed by MST

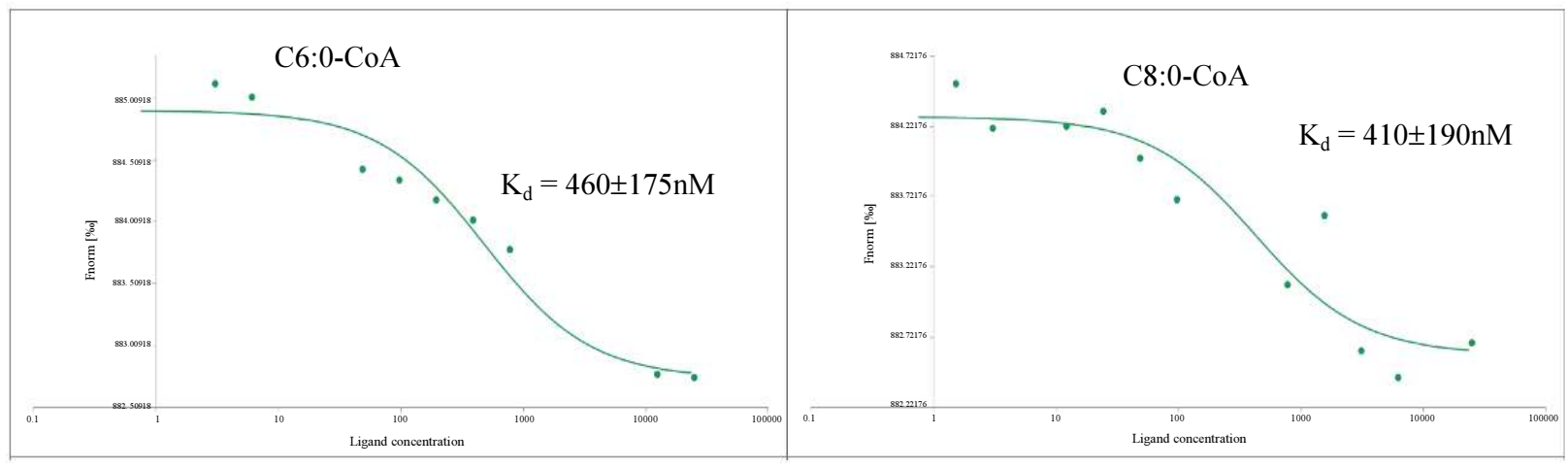




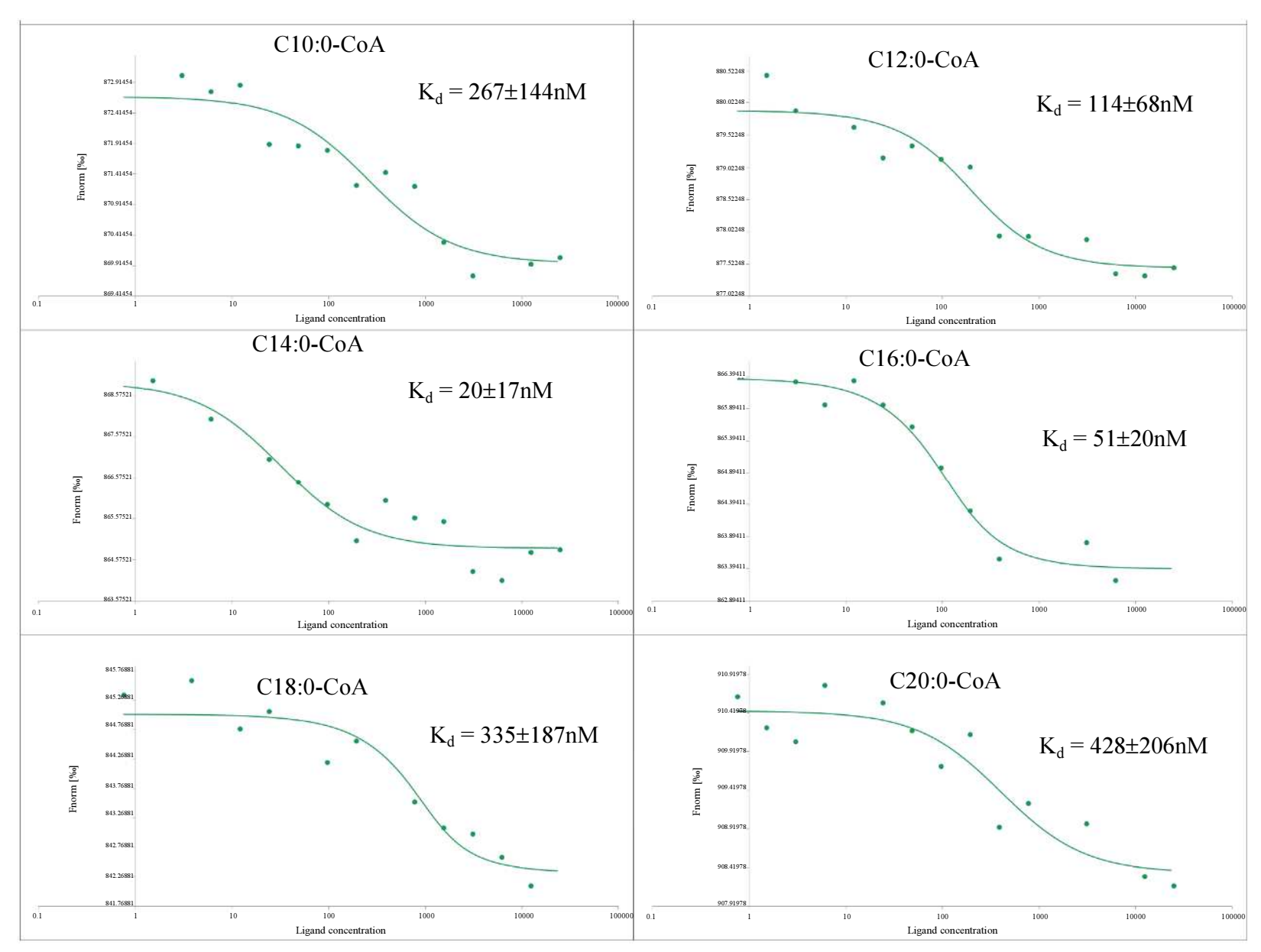

Fig. S4: Concentrationre sponse curve for MBP-ScAcbp ligand binding assessed by MST 